\title{
Cannabidiol, a Nonpsychotropic Component of Cannabis, Inhibits Cue-Induced Heroin Seeking and Normalizes Discrete Mesolimbic Neuronal Disturbances
}

\author{
Yanhua Ren, ${ }^{1}$ John Whittard, ${ }^{1}$ Alejandro Higuera-Matas, ${ }^{2}$ Claudia V. Morris, ${ }^{1}$ and Yasmin L. Hurd ${ }^{1}$ \\ ${ }^{1}$ Departments of Psychiatry and Pharmacology and Systems Therapeutics, Mount Sinai School of Medicine, New York, New York 10029-6574, \\ and 2Psychobiology Department, School of Psychology, Universidad Nacional de Educación a Distancia, 28040 Madrid, Spain
}

There remains debate regarding the impact of cannabis on neuropsychiatric disorders. Here, we examined the effects of cannabidiol (CBD), a nonpsychoactive constituent of cannabis, on heroin self-administration and drug-seeking behavior using an experimental rat model. CBD $(5-20 \mathrm{mg} / \mathrm{kg})$ did not alter stable intake of heroin self-administration, extinction behavior, or drug seeking induced by a heroin prime injection. Instead, it specifically attenuated heroin-seeking behavior reinstated by exposure to a conditioned stimulus cue. CBD had a protracted effect with significance evident after $24 \mathrm{~h}$ and even 2 weeks after administration. The behavioral effects were paralleled by neurobiological alterations in the glutamatergic and endocannabinoid systems. Discrete disturbances of AMPA GluR1 and cannabinoid type-1 receptor expression observed in the nucleus accumbens associated with stimulus cue-induced heroin seeking were normalized by CBD treatment. The findings highlight the unique contributions of distinct cannabis constituents to addiction vulnerability and suggest that CBD may be a potential treatment for heroin craving and relapse.

\section{Introduction}

There continues to be major controversy as to whether cannabis should be legalized given some of its medicinal benefits, which are countered by the negative impact of cannabis on physical and mental health. Early cannabis use is associated with the development of psychotic disorders (Andreasson et al., 1987; Arseneault et al., 2002; Hall and Degenhardt, 2008) and we and others have used experimental animal models to show that $\Delta^{9}$-tetrahydrocannabinol (THC), the psychoactive component of cannabis, can serve as a gateway to the subsequent potentiated use of heroin (Solinas et al., 2004; Ellgren et al., 2007). Most studies regarding cannabis have focused on THC with limited attention given to other constituent compounds of the cannabis plant. Cannabidiol (CBD) is also enriched in cannabis (Mechoulam, 1970), but in contrast to THC, it is nonpsychotomimetic and has antipsychotic and anxiolytic properties (Crippa et al., 2004; Zuardi et al., 2006).

In this study, we evaluated CBD effects in relation to addiction vulnerability using a drug self-administration model such that rats could directly control their drug intake and drug-seeking behavior, which characterizes the chronic, relapsing disorder of drug dependence. We focused on the potential influence of

Received Aug. 31, 2009; revised 0ct. 1, 2009; accepted 0ct. 3, 2009.

This work was supported by National Institutes of Health Grant DA19350 and funds from Mount Sinai School of Medicine. We thank Drs. Michelle Jacobs and Didier Jutras Aswad as well as other members of the Hurd lab for their input and support.

Correspondence should be addressed to Yasmin Hurd, Departments of Psychiatry, Pharmacology and Systems Therapeutics, and Neuroscience, Mount Sinai School of Medicine, One Gustave Levy Place, Box 1603, New York, NY 10029-6574. E-mail: Yasmin.Hurd@mssm.edu.

DOI:10.1523/JNEUROSCI.4291-09.2009

Copyright $\odot 2009$ Society for Neuroscience ～0270-6474/09/2914764-06\$15.00/0
CBD on heroin-related behaviors given the strong neurobiological interactions between the cannabinoid and opioid systems (Rodriguez et al., 2001; Schoffelmeer et al., 2006). CBD was studied during different behavioral phases-maintenance, extinction, and relapse. Various factors can induce drug relapse and we specifically examined the impact of drug-associated environmental cue and heroin prime that are well documented to promote drug-seeking behavior and reinstate drug intake in experimental animal models (See, 2002; Shaham et al., 2003) and to induce drug craving in humans (Childress et al., 1993; Sinha et al., 2000). Neurobiological correlates to the behavioral effects were also evaluated in the striatum, a region critical for reward, goaldirected behavior, and habit formation (Everitt and Robbins, 2005).

\section{Materials and Methods}

Animals. Male Long-Evans rats, weighing 230-250 g at the beginning of the experiment, were obtained from Taconic. They were housed in a humidity- and temperature-controlled environment on a reversed $12 \mathrm{~h}$ light/dark cycle (lights off at 9:00 A.M.) with ad libitum access to food and water. Rats were allowed to acclimate in their new environment and were handled daily for 1 week before the start of the experiment. All procedures were conducted in accordance with the National Institutes of Health Guide for the Care and Use of Laboratory Animals and approved by the local Animal Care and Use Committee.

Intravenous heroin self-administration. The self-administration procedure was performed as described previously (Ellgren et al., 2007; Spano et al., 2007). Briefly, catheters (CamCath) were implanted into the right jugular vein under isoflurane anesthesia (2.4-2.7\%; Baxter). Following 1 week of recovery from surgery, self-administration training began during the dark phase of the light/dark cycle in operant equipment which was fitted with infrared beams to measure locomotor behavior (MED Associates). Animals were allowed $3 \mathrm{~h}$ daily access to heroin $(30 \mu \mathrm{g} / \mathrm{kg} / \mathrm{infu}-$ 
a

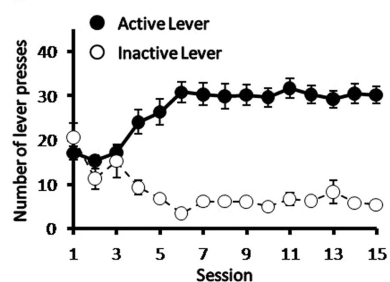

b

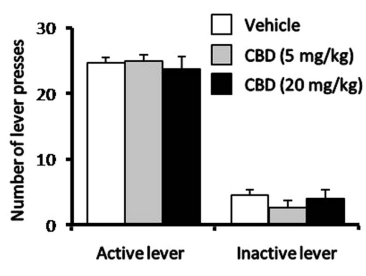

c



$\left[{ }^{35} \mathrm{~S}\right]$-uridine $5^{\prime}$-[ $\alpha$-thio $]$ triphosphate (specific activity $1000-1500 \mathrm{Ci} / \mathrm{mmol}$; New England Nuclear). The in situ hybridization procedure was similar to previously published protocols (Hurd, 2003; Ellgren et al., 2007). Briefly, the labeled probe was applied to the brain sections at a concentration of $2 \times 10^{3}$ $\mathrm{cpm} / \mathrm{mm}^{2}$ of the coverslip area. Two adjacent sections from each subject were studied. Hybridization was performed overnight at $55^{\circ} \mathrm{C}$ in a humidified chamber. After in situ hybridization, the slides were apposed to Imaging Plates (Fujifilm) along with ${ }^{14} \mathrm{C}$-standards (American Radiolabeled Chemicals). The films were developed with FLA-7000 phosphoimaging analyzer (Fujifilm) and the images were ana-

sion, diacetylmorphine-HCl; obtained from NIDA Drug Supply) under a fixed ratio-1 reinforcement schedule in which one active lever press resulted in a single drug infusion ( $85 \mu$ lover $5 \mathrm{~s})$ and activation of a white conditioned stimulus light situated above the active lever. During training, animals were food restricted $(20 \mathrm{~g} / \mathrm{d})$ and subsequently given $\mathrm{ad}$ libitum access to food after stable heroin intake behavior was achieved. Stable self-administration behavior was defined as at least 10 responses on the active lever and at least a 2:1 ratio in active:inactive lever presses for three consecutive sessions, with $<15 \%$ variation. After stable heroin intake behavior was achieved, the animals were divided into different groups balanced for the number of active lever presses to subsequently evaluate the effects of CBD $(5,20 \mathrm{mg} / \mathrm{kg}$, i.p. dissolved in 3\% Tween 80; NIDA Drug Supply) or vehicle (3\% Tween 80 ) on heroin selfadministration behavior.

In addition to the effects of CBD on heroin intake, the impact on drug-seeking behavior was also evaluated. After the drug maintenance phase, animals were kept drug-free in their home cage for 2 weeks. At the end of the drug abstinence period, drug-seeking behavior was studied during reinstatement sessions initiated by exposure to the conditioned stimulus light cue or a heroin prime injection $(0.25 \mathrm{mg} / \mathrm{kg}$, i.p.). Heroin was not delivered during the drug-seeking sessions, which lasted $1 \mathrm{~h}$, but the number of responses on both the active and inactive lever were recorded.

CBD effects were also evaluated in regard to extinction of heroin selfadministration behavior. The extinction sessions were conducted at the end of the maintenance phase of heroin self-administration, which lasted $\sim 2$ weeks. The testing conditions were the same as during training, except that presses on the previously active lever was replaced by saline infusion and there was no activation of the cue light.

Overall, 155 rats were trained to self-administer heroin in this study and 18 were excluded because of loss of catheter patency, poor health, or failure to acquire heroin self-administration.

Postmortem brain studies. To test neurobiological systems associated with CBD's effects on cue-induced heroin-seeking behavior, we studied the striatum in postmortem brain samples $1 \mathrm{~h}$ after the drug-seeking session in which rats were given vehicle or CBD. A group of saline animals were also included that were processed through the same behavioral paradigm; the rats did not show active saline self-administration behavior. At the end of drug-seeking sessions, rats were quickly killed by brief $\mathrm{CO}_{2}$ exposure and decapitation. Brains were rapidly removed, frozen in isopentane (approximately $-50^{\circ} \mathrm{C}$ ) for $10 \mathrm{~s}$, and stored at $-80^{\circ} \mathrm{C}$ until processed. Coronal sections ( $20 \mu \mathrm{m}$ thick) of the striatum were cut using a refrigerated cryostat $\left(-15^{\circ} \mathrm{C}\right.$; Frigocut $2800 \mathrm{E}$, Leica Instruments) according to the atlas of Paxinos and Watson (2005) and mounted onto Superfrost Plus slides (Brain Research Laboratories). The sections were stored at $-30^{\circ} \mathrm{C}$ until processed.

In situ hybridization histochemistry. cDNA fragments of cannabinoid $\mathrm{CB}_{1}$ receptor $\left(\mathrm{CB}_{1} \mathrm{R}\right)\left(\mathrm{NM} \_012784\right)$ and mGluR5 (NM_017012.1) were obtained from rat brain total RNA by reverse transcription-PCR using the following primer pairs: CB1, sense: $5^{\prime}$-GGGTTACAGCCTCCTTCACA-3', antisense: 5' -TGTCTCAGGTCCTTGCTCCT-3'; mGluR5, sense: $5^{\prime}$-CTGTAATACGACTCACTATAGCCCAAGCATTCGAGAAGTCTA-3', antisense: 5' -GGGATTTAGGTGACACTATAGCCAGGATGATGTACACC TT- $3^{\prime}$. The RNA probe was transcribed in the presence of lyzed by MultiGauge software (Fujifilm).

Immunohistochemistry. Brain sections were rinsed twice in PBS for 10 min each and then blocked using $5 \%(\mathrm{v} / \mathrm{v})$ heat-inactivated horse serum (Invitrogen) diluted in PBS at room temperature for $2 \mathrm{~h}$. Sections were incubated overnight at $4^{\circ} \mathrm{C}$ with antibodies directed against $\mathrm{CB}_{1} \mathrm{R}(1$ $\mu \mathrm{g} / \mathrm{ml}$ polyclonal, Millipore) or GluR1 ( $1 \mu \mathrm{g} / \mathrm{ml}$ polyclonal, Millipore) diluted in $2.5 \%(\mathrm{v} / \mathrm{v})$ heat-inactivated horse serum in PBS. Following four washes in PBS containing 0.05\% (v/v) Tween 20 (MP Biomedicals), sections were incubated with anti-rabbit or anti-mouse IRDye800CW (1:1000; Jackson ImmunoResearch Laboratories) for $2 \mathrm{~h}$ at room temperature. Following four washes, slides were allowed to dry for at least $1 \mathrm{~h}$ in the dark before imaging using the Odyssey infrared imaging system (LI-COR) at a $21 \mu \mathrm{m}$ resolution and an offset of $1.0 \mathrm{~mm}$. The level of nonspecific binding of the secondary antibodies, as assessed with brain sections incubated without primary antibody, was negligible (data not shown). An excess of blocking peptide (Millipore) was incubated with the GluR1 antibody before staining to determine the specificity of the antibody. The staining pattern with the blocking peptide was similar to that seen with brain sections incubated with secondary antibody alone (data not shown).

Data analysis. For in situ hybridization studies, the mRNA expression level was estimated within the nucleus accumbens (NAc) (bregma +2.28 to $+1.60 \mathrm{~mm}$ ) and caudate-putamen (bregma +2.28 to $+1.60 \mathrm{~mm}$ ) in accordance with the Paxinos and Watson rat brain atlas (Paxinos and Watson, 2005). Results were expressed as disintegrations per minute per milligram of tissue with reference to the coexposed standard, and values obtained from duplicate brain sections for each subject were averaged. For immunohistochemistry studies, the images were quantified using average integrated intensity values derived from regions of interest using the Odyssey application software (version 2.0; LI-COR).

Statistical analysis. For the acquisition, maintenance, and extinction of heroin self-administration studies, data were analyzed using a two-way ANOVA for repeated measures followed, when appropriate, by planned comparison tests with Bonferroni correction. For the drug-seeking studies, one-way ANOVA was used. The significance level was set at $p<0.05$. For molecular and protein studies, statistical comparison was performed by one-way ANOVA.

\section{Results}

\section{CBD specifically affects heroin-seeking behavior induced by} conditioned cue

\section{Experiment 1}

Rats quickly learned to self-administer heroin such that a significantly higher number of responses were observed on the active lever at the fourth training session (Fig. 1a) $(p<0.001)$ with stable heroin self-administered behavior acquired after the sixth session (lever presses $\times$ training session interaction; $F_{(15,315)}=$ $15.57, p<0.001)$. After acquisition of stable self-administration behavior, animals were divided into subgroups with equal heroin intake behavior to evaluate the effects of CBD or vehicle treatment. Initial CBD pilot studies indicated a greater protracted effect of the drug (data not shown), and thus the effects of CBD 
administration were examined after $30 \mathrm{~min}$ and $24 \mathrm{~h}$ time periods. The maintenance of heroin intake behavior was not affected following CBD administration (5 and $20 \mathrm{mg} / \mathrm{kg}$, i.p.) at either time point (Fig. 1b). CBD also failed to alter locomotor activity (Fig. 1c), which was simultaneously monitored during the selfadministration session.

To assess the potential impact of CBD on heroin-seeking behavior, rats were re-exposed to the heroin self-administration chamber and stimulus light cue $14 \mathrm{~d}$ following drug abstinence. During the drug-seeking session, no drug reinforcement was obtained upon lever pressing. Vehicle-treated animals showed robust lever pressing during the drug-seeking session, however, this response was inhibited by a single CBD injection administered $24 \mathrm{~h}$ (Fig. $2 a)(5 \mathrm{mg} / \mathrm{kg}, p<0.05)$, but not 30 min (data not shown), before the session. The impact of CBD on drug-seeking behavior was very specific, affecting only active lever presses following the light cue exposure (Fig. 2a) $(p<0.01)$. Various time periods were evaluated in another set of animals after CBD injections ( $5 \mathrm{mg} / \mathrm{kg}$ daily over $3 \mathrm{~d}$ ) in the reinstatement sessions. Intriguingly, there remained a significant decrease in active, but not inactive, lever presses for heroin seeking monitored even 2 weeks after the last CBD treatment (Fig. 2b) $(p<0.001)$.

To determine the effects of CBD on other conditions known to induce relapse, additional sets of animals were tested during a drug-seeking session that was initiated by a heroin prime injection $(0.25 \mathrm{mg} /$ $\mathrm{kg}$, i.p.). CBD, both acute and $24 \mathrm{~h}$ after injection, had no effect on either active or inactive lever presses following the heroin prime (data not shown).

\section{Experiment 2}

The impact of CBD on extinction of heroin self-administration was also examined in which the context of the self-administration chamber, but not the cue light, was extinguished. CBD injections given $24 \mathrm{~h}$ before the initial extinction session and daily throughout the extinction training did not alter the rate of decline in the active lever-pressing or alter the inactive lever press responses compared with vehicle control animals (Fig. $3 a$ ). After a 2 week abstinence period, re-exposure to the cue light reinstated lever pressing in vehicle animals, but this was attenuated in animals administered CBD $24 \mathrm{~h}$ before the relapse session (Fig. 3b) $(p<$ 0.01 ). Animals carried through the extinction paradigm were also exposed to a drug-seeking session that was initiated by a heroin prime injection $(0.25 \mathrm{mg} / \mathrm{kg}$, i.p.). CBD, both acute (data not shown) and $24 \mathrm{~h}$ after injection, had no effect on either active or inactive lever presses (Fig. $3 c$ ) induced by the heroin prime.

Altogether, these results suggest that CBD has a protracted neurobiological effect to counter long-lasting neuroadaptations that specifically govern conditioned cue-induced drug-seeking behavior and relapse.

\section{CBD effects on mesolimbic CB1 and GluR1 receptors}

$\mathrm{CBD}$ has been reported to be an inverse agonist at $\mathrm{CB}_{1} \mathrm{Rs}$ (Thomas et al., 2007) and an agonist at the transient receptor potential V1 (TRPV1) and TRPV2 (Qin et al., 2008). We examined the striatum, a region critical for reward, goal-directed be0.001 versus vehicle. a

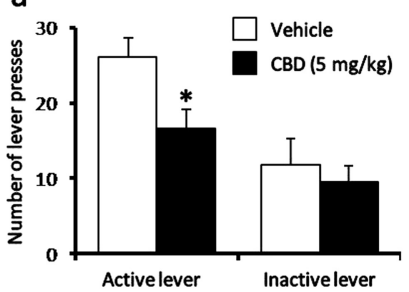

b

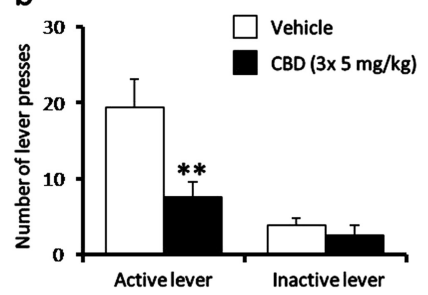

Figure 2. CBD inhibits cue-induced heroin-seeking behavior. $\boldsymbol{a}, \boldsymbol{b}, \mathrm{CBD}$ reduced the number of active lever presses induced by exposure to a stimulus light cue $24 \mathrm{~h}$ before testing $(\boldsymbol{a})$ and 2 weeks following last repeated CBD injection $(\boldsymbol{b} ; 5 \mathrm{mg} / \mathrm{kg}$, daily during the final $3 \mathrm{~d}$ of heroin self-administration maintenance; $3 \times$ ). Data represent mean \pm SEM; $n=7-9 /$ group. ${ }^{*} p<$ $0.05,{ }^{* *} p<0.01,{ }^{* * *} p<0.001$ versus vehicle. a Active: $\Delta$ Vehicle $C \mathrm{CBD}(10 \mathrm{mg} / \mathrm{kg}) \quad \mathrm{CBD}(20 \mathrm{mg} / \mathrm{kg}) \quad$ b
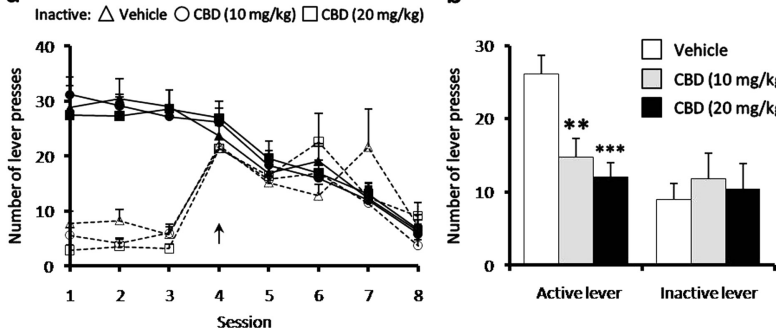

C

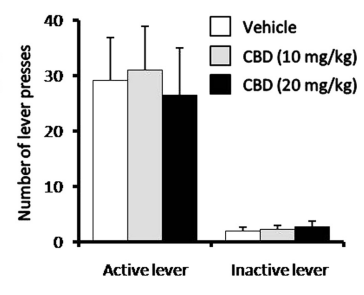

Figure 3. CBD effects on extinction behavior. $\boldsymbol{a}, \boldsymbol{b}, \mathrm{CBD}(10$ and $20 \mathrm{mg} / \mathrm{kg}$, i.p.) did not affect lever pressing during extinction

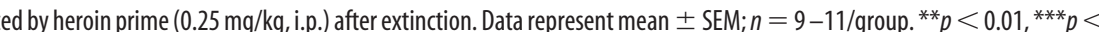

havior, and habit formation (Everitt and Robbins, 2005), in animals following the drug-seeking session. TRP proteins and mRNA levels were extremely low in the forebrain, though they were detected in the dorsal root ganglion (data not shown). $\mathrm{CB}_{1} \mathrm{R}$ mRNA expression was significantly increased in the ventral striatum (NAc), the core subdivision in heroin rats that received vehicle treatment before drug seeking (Fig. $4 a)(p<0.05)$. The heroin-CBD group showed decreased $\mathrm{CB}_{1} \mathrm{R}$ mRNA expression in the NAc core and shell subdivisions compared with heroinvehicle animals even 2 weeks after the last CBD injection (Fig. $4 a$ ) $(p<0.05$ and $p<0.01)$. Moreover, this CBD effect was also evident in the most medial division of the dorsal striatum $(p<$ $0.05)$, which is innervated by limbic cortices, but no CBD effects were evident in the dorsolateral division that receives primarily sensorimotor cortical input (supplemental Table 1, available at www.jneurosci.org as supplemental material). Similar to alterations of the $C_{1} R$ transcript, $C B_{1} R$ protein levels tended to be increased in the NAc of heroin-vehicle animals (Fig. $4 b, c$ ) (significant in the lateral NAc shell; $p<0.05$ ), which were decreased both $24 \mathrm{~h}$ and 2 weeks after CBD treatment [medial $(p<0.05)$ and lateral $(p<0.01)$ NAc shell]. These findings suggest that CBD's effects on $\mathrm{CB}_{1} \mathrm{R}$ expression have a mesolimbic specificity in the striatum. Interestingly, $\mathrm{CBD}$ administered in heroin-naive animals acutely reduced $\mathrm{CB}_{1} \mathrm{R}$ expression in the NAc but not in the dorsal striatum; no significant alterations were observed with repeated CBD exposure (supplemental Table 2, available at www. jneurosci.org as supplemental material).

Drug-seeking behavior and relapse have been strongly linked to dysregulation of glutamate (Kalivas and Volkow, 2005; LaLumiere and Kalivas, 2008). We studied mRNA and protein levels of several markers relevant to glutamatergic function; 



Figure 4. $\quad\left(B D\right.$ effects on $C_{1} R$ and glutamate receptor expression in relation to cue-induced heroin-seeking behavior. $\boldsymbol{a}-\boldsymbol{c}, \mathrm{CB}_{1} R \mathrm{RNA}(\boldsymbol{a})$ and protein ( $\boldsymbol{b}$ and $\left.\boldsymbol{c}\right)$ levels in the NAc following either vehicle or CBD administration $24 \mathrm{~h}(1 \times)$ before the cue-induced drug-seeking session. $\boldsymbol{d}-\boldsymbol{f}$, mGluR5 RNA levels $(\boldsymbol{d})$ and GluR1 protein levels $(\boldsymbol{e}$ and $\boldsymbol{f})$. Data represent mean \pm SEM; $n=4-8 / \mathrm{group}$. NAc-c, NAc core; M/L-NAc-s, medial/lateral NAc shell; (P, caudate-putamen (dorsal striatum); SA, self-administration. ${ }^{*} p<0.05,{ }^{* *} p<0.01,{ }^{* * *} p<0.001$ versus vehicle; ${ }^{\#} p<0.01$ versus heroin-vehicle.

markers related to opioid transmission were also evaluated given the relevance to heroin. Most showed only heroin-associated effects with no alterations induced by CBD. For example, mRNA levels of mGluR5, abundantly expressed in medium spiny striatal efferent neurons and intricately linked to endocannabinoidmediated synaptic plasticity (Katona and Freund, 2008), were strongly downregulated to the same extent in the heroin-vehicle and heroin-CBD groups (Fig. $4 d)(p<0.001)$. In contrast, AMPA GluR1 receptors, which are highly implicated in drugseeking behavior (Conrad et al., 2008), were significantly altered only in the heroin-CBD animals; GluR2/3 were not robustly expressed in the striatum and $\mathrm{CDB}$ administration on its own did not alter expression levels of any of the glutamatergic markers studied (data not shown). As shown in Figure 4, $e$ and $f$, heroinvehicle animals, with strong cue-induced relapse behavior, had marked reduction of AMPA GluR1 protein expression in the NAc core $(p<0.001)$, medial shell $(p<0.01)$, and lateral shell $(p<$ 0.05 ), with no significant effect in the dorsal striatum (supplemental Table 1, available at www.jneurosci.org as supplemental material). However, $24 \mathrm{~h}$ after CBD, GluR1 protein expression was significantly normalized in the NAc core $(p<0.001)$ and medial shell $(p<0.05)$. A similar pattern was observed even 2 weeks following the last repeated CBD treatment, but the effect was most evident in the NAc core (Fig. $4 e)(p<0.01)$.

\section{Discussion}

The current study has revealed unique properties of the phytocannabinoid CBD and underscores the contrasting characteristics of the main constituents of cannabis in relation to addiction vulnerability. Compared with the documented effects of THC to enhance heroin self-administration (Solinas et al., 2004; Ellgren et al., 2007), the present data demonstrated that CBD specifically inhibited reinstatement of cue-induced heroin seeking. The specificity of CBD to cue-induced reinstatement was also emphasized by the observation that the compound still inhibited drug relapse behavior in animals extinguished to the environmental context (self-administration chamber) previously associated with heroin. The results are striking given the very selective and protracted effects of CBD. Although CBD significantly altered drug-seeking behavior promoted by conditioned cue, it failed to influence drug seeking initiated by a heroin prime. Whether CBD induces some perceptual alterations that compromise cue- but not priminginduced reinstatement of drug seeking remains to be determined. The apparent diminished impact of $\mathrm{CBD}$ in the presence of heroin was also evident during the drug maintenance phase, in which $\mathrm{CBD}$ did not modify stable heroin intake behavior. Thus CBD does not appear to interfere with the reinforcing effects of heroin at least on a FR-1 schedule. Interestingly, the ability of CBD to reduce heroin-seeking behavior at least 2 weeks after exposure was nevertheless still observed when CBD had been administered during the active phase of heroin selfadministration. These findings emphasize that $\mathrm{CBD}$ retains its effects to modulate neural mechanisms relevant to cue-induced drug relapse vulnerability even in the presence of heroin.

The observation that CBD's effects on cue-induced drugseeking behavior was apparent $24 \mathrm{~h}$ and 2 weeks, but not after 30 min, following administration may suggest delayed pharmacological actions of the drug. However, it is important to note that behavioral effects have been observed immediately after administration of $\mathrm{CBD}$ at the dose range currently studied on, for example, its anxiolytic properties (Guimarães et al., 1994; Moreira et al., 2006). Moreover, acute administration of CBD has been shown to enhance the extinction of cocaine- and amphetamineinduced conditioned place preference without affecting learning or retrieval (Parker et al., 2004). There was also no evidence in our study that $\mathrm{CBD}$ affected extinction learning. CBD did not alter the extinction of heroin seeking. The potential influence of CBD 
on psychostimulant-seeking behavior needs to be examined with an operant self-administration procedure to determine the specificity of CBD to different classes of drugs and different relapse models.

The protracted behavioral effects of $\mathrm{CBD}$, in addition to its specific influence on heroin-seeking behavior, strongly implied a long-term impact on synaptic plasticity, the pathology of which is hypothesized to underlie compulsive disorders such as drug addiction. The endocannabinoid and glutamatergic systems have been tightly linked to synaptic plasticity (Kauer and Malenka, 2007). In addition to its high potency at the $\mathrm{CB}_{1} \mathrm{R}$ (Thomas et al., 2007), CBD has also been reported to alter the hydrolysis of the endocannabinoid anandamide (Bisogno et al., 2001). The reduction of $\mathrm{CB}_{1} \mathrm{R}$ expression in the NAc when $\mathrm{CBD}$ was administered alone was short-term though its impact was enduring in heroinseeking animals. Attenuation of the elevated expression $\mathrm{CB}_{1} \mathrm{R}$ mRNA and protein levels in the NAc by CBD in heroin rats, which paralleled the behavioral alterations, is consistent with the observation that inhibition of the $\mathrm{CB}_{1} \mathrm{R}$ inhibits cue-induced drug-seeking behavior (De Vries et al., 2003).

Various lines of evidence have clearly documented the critical role of AMPA GluR1 in drug-seeking behavior though most studies have focused on psychostimulant drugs (Anderson et al., 2008; Conrad et al., 2008). Of the few investigations that have evaluated opiates, the expression of AMPA receptors in prefrontal cortical synaptic membranes was reported to be reduced in heroin-abstinent animals after re-exposure to heroin cues (Van den Oever et al., 2008) and glutamate arising from the prefrontal cortex was increased in the NAc core (LaLumiere and Kalivas, 2008). The specific cellular localization of the GluR1 was not examined in the current study, which limits interpretations as to the dynamic cellular distribution of AMPA receptors relevant to drug-seeking behavior. Moreover, it is important to note that a similar alteration of glutamate levels was reported in the NAc core with both cue and heroin prime (LaLumiere and Kalivas, 2008). Thus, other mechanisms than NAc core glutamatergic disturbances most likely underlie CBD's apparent ability to alter cue- but not priming-induced reinstatement of drug seeking. Nevertheless, the observation that GluR1 disturbances in the NAc associated with heroin seeking were absent in those administered $\mathrm{CBD}$ is intriguing. Most studies have focused on the NAc core in relation to glutamatergic involvement in drug-seeking behavior, but CBD's effects on GluR1 were also apparent in the NAc shell, though to a weaker extent than the core. Further studies are required to determine the specific contribution of the NAc subregions as well as other brain regions implicated in cue-induced reinstatement to the actions of CBD. Although additional studies are needed to fully elucidate the molecular mechanisms of CBD in regard to its direct and indirect effects on heroin-seeking behavior, the mesolimbic specificity and protracted effects of CBD on $\mathrm{CB}_{1} \mathrm{R}$ and GluR1 is interesting given the role of the limbic system in goal-directed behavior.

Of the over 1 million opiate-dependent subjects today, only less than a quarter of such individuals receive treatment, which have traditionally targeted $\mu$-opioid receptors. Although such treatment strategies including methadone have improved substance abuse outcome, they do not effectively block opiate craving in all patients (Walter et al., 2008) and thus are still associated with high rates of relapse and ultimately the continued cycle of opioid abuse. The fact that drug craving is generally triggered by exposure to conditioned cues makes the current results particularly fascinating. Moreover, the observation that CBD did not cause gross motor impairment as evident by a lack of effect on inactive lever presses or on locomotor behavior is consistent with the weak side effects that have been reported with this compound in humans (Consroe et al., 1991; Tomida et al., 2006). In addition, CBD lacks hedonic properties on its own (Parker et al., 2004). Overall, the observations of this study suggest the potential for $\mathrm{CBD}$ as a treatment strategy given its specificity to attenuate cue-induced drug-seeking behavior, preferential impact on mesolimbic neuronal populations, and enduring neural actions. Clearly, greater attention needs be given to the potential role of CBD in the treatment of addiction and other mental health disorders.

\section{References}

Anderson SM, Famous KR, Sadri-Vakili G, Kumaresan V, Schmidt HD, Bass CE, Terwilliger EF, Cha JH, Pierce RC (2008) CaMKII: a biochemical bridge linking accumbens dopamine and glutamate systems in cocaine seeking. Nat Neurosci 11:344-353.

Andreasson S, Allebeck P, Engstrom A, Rydberg U (1987) Cannabis and schizophrenia. A longitudinal study of Swedish conscripts. Lancet 2:1483-1486.

Arseneault L, Cannon M, Poulton R, Murray R, Caspi A, Moffitt TE (2002) Cannabis use in adolescence and risk for adult psychosis: longitudinal prospective study. BMJ 325:1212-1213.

Bisogno T, Hanus L, De Petrocellis L, Tchilibon S, Ponde DE, Brandi I, Moriello AS, Davis JB, Mechoulam R, Di Marzo V (2001) Molecular targets for cannabidiol and its synthetic analogues: effect on vanilloid VR1 receptors and on the cellular uptake and enzymatic hydrolysis of anandamide. Br J Pharmacol 134:845-852.

Childress AR, Hole AV, Ehrman RN, Robbins SJ, McLellan AT, O’Brien CP (1993) Cue reactivity and cue reactivity interventions in drug dependence. NIDA Res Monogr 137:73-95.

Conrad KL, Tseng KY, Uejima JL, Reimers JM, Heng LJ, Shaham Y, Marinelli M, Wolf ME (2008) Formation of accumbens GluR2-lacking AMPA receptors mediates incubation of cocaine craving. Nature 454:118-121.

Consroe P, Laguna J, Allender J, Snider S, Stern L, Sandyk R, Kennedy K, Schram K (1991) Controlled clinical trial of cannabidiol in Huntington's disease. Pharmacol Biochem Behav 40:701-708.

Crippa JA, Zuardi AW, Garrido GE, Wichert-Ana L, Guarnieri R, Ferrari L, Azevedo-Marques PM, Hallak JE, McGuire PK, Filho Busatto G (2004) Effects of cannabidiol (CBD) on regional cerebral blood flow. Neuropsychopharmacology 29:417-426.

De Vries TJ, Homberg JR, Binnekade R, Raaso H, Schoffelmeer AN (2003) Cannabinoid modulation of the reinforcing and motivational properties of heroin and heroin-associated cues in rats. Psychopharmacology (Berl) 168:164-169.

Ellgren M, Spano SM, Hurd YL (2007) Adolescent cannabis exposure alters opiate intake and opioid limbic neuronal populations in adult rats. Neuropsychopharmacology 32:607-615.

Everitt BJ, Robbins TW (2005) Neural systems of reinforcement for drug addiction: from actions to habits to compulsion. Nat Neurosci 8:1481-1489.

Guimarães FS, de Aguiar JC, Mechoulam R, Breuer A (1994) Anxiolytic effect of cannabidiol derivatives in the elevated plus-maze. Gen Pharmacol 25:161-164.

Hall W, Degenhardt L (2008) Cannabis use and the risk of developing a psychotic disorder. World Psychiatry 7:68-71.

Hurd YL (2003) In situ hybridization with isotopic riboprobes for detection of striatal neuropeptide mRNA expression after dopamine stimulant administration. Methods Mol Med 79:119-135.

Kalivas PW, Volkow ND (2005) The neural basis of addiction: a pathology of motivation and choice. Am J Psychiatry 162:1403-1413.

Katona I, Freund TF (2008) Endocannabinoid signaling as a synaptic circuit breaker in neurological disease. Nat Med 14:923-930.

Kauer JA, Malenka RC (2007) Synaptic plasticity and addiction. Nat Rev Neurosci 8:844-858.

LaLumiere RT, Kalivas PW (2008) Glutamate release in the nucleus accumbens core is necessary for heroin seeking. J Neurosci 28:3170-3177.

Mechoulam R (1970) Marihuana chemistry. Science 168:1159-1166.

Moreira FA, Aguiar DC, Guimarães FS (2006) Anxiolytic-like effect of cannabidiol in the rat Vogel conflict test. Prog Neuropsychopharmacol Biol Psychiatry 30:1466-1471. 
Parker LA, Burton P, Sorge RE, Yakiwchuk C, Mechoulam R (2004) Effect of low doses of delta9-tetrahydrocannabinol and cannabidiol on the extinction of cocaine-induced and amphetamine-induced conditioned place preference learning in rats. Psychopharmacology (Berl) 175:360 366.

Paxinos G, Watson C (2005) The rat brain in stereotaxic coordinates, Ed 5. Amsterdam: Elsevier.

Qin N, Neeper MP, Liu Y, Hutchinson TL, Lubin ML, Flores CM (2008) TRPV2 is activated by cannabidiol and mediates CGRP release in cultured rat dorsal root ganglion neurons. J Neurosci 28:6231-6238.

Rodriguez JJ, Mackie K, Pickel VM (2001) Ultrastructural localization of the $\mathrm{CB} 1$ cannabinoid receptor in $\mu$-opioid receptor patches of the rat caudate putamen nucleus. J Neurosci 21:823-833.

Schoffelmeer AN, Hogenboom F, Wardeh G, De Vries TJ (2006) Interactions between CB1 cannabinoid and mu opioid receptors mediating inhibition of neurotransmitter release in rat nucleus accumbens core. Neuropharmacology 51:773-781.

See RE (2002) Neural substrates of conditioned-cued relapse to drugseeking behavior. Pharmacol Biochem Behav 71:517-529.

Shaham Y, Shalev U, Lu L, De Wit H, Stewart J (2003) The reinstatement model of drug relapse: history, methodology and major findings. Psychopharmacology (Berl) 168:3-20.

Sinha R, Fuse T, Aubin LR, O’Malley SS (2000) Psychological stress, drug-related cues and cocaine craving. Psychopharmacology (Berl) 152:140-148.
Solinas M, Panlilio LV, Goldberg SR (2004) Exposure to delta-9tetrahydrocannabinol (THC) increases subsequent heroin taking but not heroin's reinforcing efficacy: a self-administration study in rats. Neuropsychopharmacology 29:1301-1311.

Spano MS, Ellgren M, Wang X, Hurd YL (2007) Prenatal cannabis exposure increases heroin seeking with allostatic changes in limbic enkephalin systems in adulthood. Biol Psychiatry 61:554-563.

Thomas A, Baillie GL, Phillips AM, Razdan RK, Ross RA, Pertwee RG (2007) Cannabidiol displays unexpectedly high potency as an antagonist of CB1 and CB2 receptor agonists in vitro. Br J Pharmacol 150:613-623.

Tomida I, Azuara-Blanco A, House H, Flint M, Pertwee RG, Robson PJ (2006) Effect of sublingual application of cannabinoids on intraocular pressure: a pilot study. J Glaucoma 15:349-353.

Van den Oever MC, Goriounova NA, Li KW, Van der Schors RC, Binnekade R, Schoffelmeer AN, Mansvelder HD, Smit AB, Spijker S, De Vries TJ (2008) Prefrontal cortex AMPA receptor plasticity is crucial for cueinduced relapse to heroin-seeking. Nat Neurosci 11:1053-1058.

Walter M, Wiesbeck GA, Bloch N, Aeschbach S, Olbrich HM, Seifritz E, Dürsteler-MacFarland KM (2008) Psychobiological responses to drug cues before and after methadone intake in heroin-dependent patients: a pilot study. Eur Neuropsychopharmacol 18:390-393.

Zuardi AW, Hallak JE, Dursun SM, Morais SL, Sanches RF, Musty RE, Crippa JA (2006) Cannabidiol monotherapy for treatment-resistant schizophrenia. J Psychopharmacol 20:683-686. 